\title{
Learning to care for those who can't be cured
}

Canada's medical schools will soon teach the next generation of doctors how to care for those who can't be cured.

"Physicians have not been taught to deal with death," says Dr. Larry Librach, director of the Temmy Latner Centre for Palliative Care at Toronto's Mount Sinai Hospital. "We've been cure-focused."

In response to a submission by the Association of Canadian Medical Colleges (ACMC) and the Canadian Hospice Palliative Care Association (CHPCA), Health Canada recently announced it will commit $\$ 1.25$ million over 5 years to ensure medical students get training in treating the terminally ill. Medical schools have already begun integrating the program into their curricula.
"We have a central project team and local teams in every medical school now - all 17 schools," said Librach, a CHPCA board member and 27year palliative care practitioner. "When students graduate, they will have basic core competencies in palliative care, as will every clinical postgrad trainee."

Palliative care experts credit Manitoba Senator Sharon Carstairs, who chaired a Senate committee that produced the bombshell 2000 report Quality End-of-Life Care: the Right of Every Canadian, for highlighting the need for the training.

Palliative care training will become as essential as vaccines in a physician's education. "It will just be part of the drill," said Dr. David Hawkins, executive director of the ACMC.
Exposure to the precepts of palliative care could also encourage more medical students to enter what, given the aging population, is a growing field. "But you will never get enough specialists," Librach says, "so we would like every physician to have the basic skills."

Although pain control used to be the most important issue doctors addressed in caring for the dying, it is now just one element of what they learn.

People "have spiritual, emotional, psychological needs," says Librach. "We need to help people address their issues of suffering and address the end of life - to help people and their families understand that dying is part of life. The soul needs more than morphine." - Foe Sornberger, Ottawa

\section{Public Health}

\section{Varicella vaccine cost-effective: US study}

A new US study concluding that chickenpox vaccination programs can save millions in direct medical costs comes at a time when more Canadian jurisdictions are adding varicella to their list of covered immunizations.

The study, published in the September issue of Pediatrics (114[3]:786-92), examined hospitalization and financial charge data from 1993-2001. In 1995, live attenuated varicella vaccine was universally recommended for children. The study concludes that hospital admission rates for chickenpox and related complications dropped 74\% between 1995 and 2001, and saved almost $\$ 100$ million. The current vaccination rate in the US has climbed to $85 \%$ for children aged $19-35$ months (44 states have made it mandatory for school enrolment).

"Not only children but adolescents and adults appear to have benefited from lower hospitalization rates for chickenpox in the vaccine era," Dr. Matthew Davis, lead author of the study and a pediatrician at the University of Michigan's C.S. Mott Children's Hospital, told CMA7.

The study found the US public insurance program (Medicaid) benefited the most from reduced hospitalization rates and charges.

The results should quell the scepticism of some parents and physicians about whether a varicella vaccination program is worthwhile, says Davis.

Dr. Arlene King, director of Immunization and Respiratory Infection at Health Canada, calls the conclusions striking. "We knew that varicella immunizations were cost effective if you included indirect costs," she says, "but it exceeds our expectations insofar as this looks to be cost effective even when you just consider the health care costs, which is really terrific news. Health care systems like to see the impact on their expenditures."

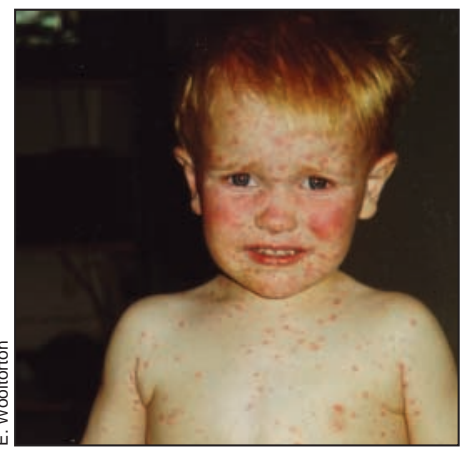

Varicella vaccination saved almost $\$ 100$ million by reducing hospital admission rates.

Canadian jurisdictions are working toward coast-to-coast varicella vaccine coverage by 2005. This year Ottawa established a \$300-million, 3-year national immunization program.

Only Newfoundland and Labrador, BC and Quebec have not yet announced varicella vaccine coverage, but programs are pending. - Pauline Comeau, Ottawa 